\title{
Phenol Administration in Adolescents with Pilonidal Sinus is Effective and Related to High Patient Satisfaction Rates
}

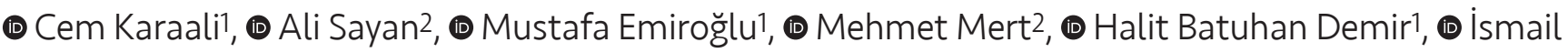 \\ Sert¹, (1) Gökhan Köylüoğlu33, (1) Cengiz Aydın
}

1University of Health Sciences Turkey, İzmir Tepecik Training and Research Hospital, Clinic of General Surgery, Izmir, Turkey 2University of Health Sciences Turkey, İzmir Tepecik Training and Research Hospital, Clinic of Pediatric Surgery, İzmir, Turkey ${ }^{3}$ Katip Çelebi University, Department of Pediatric Surgery, İzmir, Turkey

\begin{abstract}
Aim: Surgical methods are the most commonly used methods in the treatment of pilonidal sinus (PS) in the world but their recovery durations and return to work/school periods are long and the complication rates are high. Among minimally invasive methods, phenol therapy is frequently used in adults and successful results are reported. However, studies on phenol treatment in adolescents with PS are limited and their number of patients is small. Therefore, our study aims to determine whether $80 \%$ liquid phenol treatment can be used as first-line therapy in this age group.

Materials and Methods: Primary and 9 between 14 and 19 years who were treated with $80 \%$ liquid phenol were included in this study. Patient data were obtained from their files retrospectively.

Results: Of the patients, 69 (69.7\%) were male and 30 (30.3\%) were female. The mean age of the patients was $17.4 \pm 1.3$ (minimum-maximum 14-19). The total recurrence and complication rates after phenol administration were $10.7 \%$ and $16.1 \%$, respectively. According to the Likert-type questionnaire, the mean satisfaction rate was 8.7 \pm 1.7 (minimum-maximum 5-10).

Conclusion: In our study, it has been shown that $80 \%$ liquid phenol treatment can be successfully applied in adolescents with PS with low recurrence and low major complication rates. In addition, we think that $80 \%$ liquid phenol treatment should be recommended as the first-line treatment option for both primary and postoperative recurrent adolescent patients with PS, as it ensures a quicker return to work/school and shows high satisfaction rates.
\end{abstract}

Keywords: Adolescence, phenol, pilonidal sinus

\section{Introduction}

Pilonidal sinus (PS) disease is a chronic inflammatory disease that usually affects young men in their twenties. The disease usually manifests itself with chronic inflammatory discharges of the sinuses or acute developing abscesses and can be asymptomatic as well. Although there is no advantage in treating asymptomatic disease, patients with symptomatic disease should be treated (1). In spite of the fact that many methods have been described for the treatment of PS, optimal treatment is still controversial. The ideal PS treatment should be a method that can be applied with minimal tissue excision, offers good cosmetic 
results, does not require hospitalization, has a low-cost, is easy to use, allows a rapid return to work/school, and has low complication and recurrence rates $(2,3)$.

The main goal of surgical treatment methods is to excise PS and then leaving this area to secondary healing or to close this area with flap or flapless methods $(1,4-6)$. However, none of these surgical methods provide 100\% improvement, so to perform the operation, hospitalization is required, patients cannot return to work for a long time and recovery periods are defined in weeks (1,4-7). In addition, postoperative complication rates are found to be $8.9-49 \%(4,5)$. In spite of this, surgery is still the most common treatment in PS (1).

Besides surgical treatments, phenol application has been used for the treatment of adult PS patients for a long time as a simple and easy to use method with high success rates $(3,8,9)$. In the literature, the number of studies evaluating the adolescent patient group with phenol was limited and the published works focus on the use of phenol in a crystallized state (10-12). As far as we can see, there are no papers with liquid phenol in the adolescent PS literature. Our study aims to discuss the efficacy and satisfaction rate of $80 \%$ liquid phenol application in patients with adolescent PS in the light of the literature and to determine whether liquid phenol treatment is a usable method in this age group.

\section{Materials and Methods}

Local ethics committee approval (26.09.2018-252) was obtained for this study. Between January 2013 and January 2018, adolescent patients aged between 14 and 19 years who applied to a $3^{\text {rd }}$ step reference hospital for primary or recurrent PS and who accepted to be treated by the phenol method were included. The patients' data were collected by one physician's personal log and analyzed retrospectively. Demographic data, comorbidities, body mass index (BMI), complications and PS recurrences were evaluated.

None of the patients underwent preoperative prophylactic antibiotic or laboratory tests. The differential diagnosis of anal fistula in the patients with sinus located near the anal canal was ruled out by magnetic resonance imaging. $80 \%$ liquid phenol was applied by the same physician to all patients. After phenol administration, patients were called for twice in the first week, then weekly until the wound was closed, and at $2^{\text {nd }}, 6^{\text {th }}$ and $12^{\text {th }}$ months after the wound was closed. After that, patients were called for check-up only once a year. The closure of the wound within 2 months or the failure to reopen within this period was defined as recovery. Patients with recurrent or non-healing wounds were treated with phenol for a second and/or third time. By applying a Likert-type satisfaction questionnaire to patients who came to the check-up postoperatively, the patients were asked to evaluate their outcomes in terms of procedure tolerance, postoperative pain, complication, return to daily work and cosmetic appearance (0-2; poor, 3-4; fair, 5-6; average, 7-8; good; $9-10$ excellent). Finally, the patients were invited to the outpatient clinic with the purpose of evaluating their recurrences and complaints. In the situation of those who could not come to the polyclinic, patients were interviewed by telephone.

Patients who had acute inflammation or abscess at the beginning of the treatment, those who did not come to the follow-up check-ups, and those who had no contact information or could not be reached were not included in this study. In addition, patients who had developed recurrence after phenol treatment and then preferred another treatment instead of phenol for the $2^{\text {nd }}$ and/or $3^{\text {rd }}$ time were excluded from the study.

\section{Statistical Analysis}

Statistical analyzes were performed using SPSS version 17.0 software. The conformity of the variables to normal distribution was examined using analytical methods (Kolmogorov-Smirnov/Shapiro-Wilk tests). Descriptive analyzes were given as mean \pm standard deviation for variables that were not normally distributed. Descriptive statistics were made by giving demographic characteristics, frequency and percentage values. In continuous data, independent groups t-test was used to compare binary groups such as "yes" or "no". Pearson's chi-square or Fisher's Exact chi-square test was used in the analysis of categorical data. The cases where the p-value was below 0.05 were considered statistically significant.

\section{PS Treatment Technique with Phenol}

All patients were treated in a day surgery unit. Written informed consent was obtained from all patients before the procedure. After positioning the patient in the Jackknife position, hair was removed from the presacral area and local anesthesia was applied. During the phenol application, petroleum jelly (Vaseline; Unilever, London, UK) and dry dressing were used to protect the circumjacent healthy tissue and anal region. Those with narrow sinus mouths were either dilated with a small incision $(0.5-1 \mathrm{~cm})$ to remove hair from these openings, and then the cavity was debrided. Bleeding from these procedures was stopped by 
electrocautery or pressure. After $80 \%$ liquid phenol was impregnated into the swab cotton, it was gently pressed onto the cavity and held for approximately 2 minutes. This procedure was repeated 3 or 4 times. After the procedure was completed, by gently pressing on top of the cavities, the remaining phenol and debris were removed. This area was covered with dry dressing. Patients were given painkillers to use when necessary. None of the patients were prescribed oral antibiotics or pomade with local antibiotics. During the first follow-up on postoperative day 3 , a gentle debridement was performed and the debris remaining inside was removed by entering from the sinus using clamps without any local anesthesia. No physical restraint was recommended to the patients in the postoperative period, and they could return to their work/school and daily activities immediately or when they felt ready.

\section{Results}

Of the patients, 69 (69.7\%) were male and 30 (30.3\%) were female. The mean age of the patients was $17.4 \pm 1.3$ years (miimumn-maximum 14-19). While 77 patients (77.8\%) had primary PS, 22 (22.2\%) patients had recurrent PS disease after surgical intervention. Co-morbidities were found in 11 patients (coeliac disease, leukemia, myasthenia gravis, insulin resistance, familial Mediterranean fever and asthma). The mean BMI was found to be $25 \pm 4.1$ (16-37) (Table I).

The rate of recurrence after the first phenol administration was $26.2 \%$ (99/26). Four of the patients who incurred recurrence after the first application of phenol were discharged from the study because they wanted surgery and two patients were excluded because they did not come to follow-up. Among the remaining 93 patients, recurrence rates were found to be 14\% (93:13) and 10.7\% (93:10), respectively, when second and third phenol were administered to those patients with recurrence. A total of $15(16.1 \%)$ patients developed complications following the

\begin{tabular}{|l|l|}
\hline \multicolumn{2}{|l|}{ Table I. Patient and PS characteristics } \\
\hline Average age, $\mathrm{n}(\%)$ & min.-max. 14-19 mean 17.48 \pm 1.3 \\
\hline Male/female ratio \% & $69 / 30$ \\
\hline BMI, n (median) & min.-max. 16-37 \\
\hline & Mean 25 \pm 4.1 \\
\hline Additional morbidity, n (\%) & $11(11.1 \%)$ \\
\hline Primary PS, $\mathrm{n}(\%)$ & $77(77.8 \%)$ \\
\hline Recurrent PS, $\mathrm{n}(\%)$ & $22(22.2 \%)$ \\
\hline (Before phenol application, all surgical operations) \\
\hline PS: Pilonidal sinus, BMI: Body mass index, min: Minimum, max: Maximum \\
\hline
\end{tabular}

procedure. Eleven (11.8\%) patients with minor complications who developed maceration and superficial burns were treated with routine dressings. Oral antibiotics were given to $2(2.1 \%)$ patients who developed cellulitis. Two (2.1\%) patients developed abscesses, which were drained, and they used oral antibiotic. According to the Likert-type questionnaire, the mean satisfaction rate was $8.7 \pm 1.7$ (minimum-maximum 5-10) (Table II).

Recurrence and complications were compared in terms of age, gender, BMl, time from the onset of complaints to admission to the hospital, natal cleft depth, sinus number and location, smoking, abscess drainage before phenol administration, how many baths the patient takes a week, surgery before phenol administration and whether relatives have PS (Table III). There was only a significant relationship between smoking and total complication rates $(p<0.05)$.

\section{Discussion}

Our study emphasizes that phenol therapy can be used successfully in adolescent patients with PS and highlights that it may be an alternative to surgical treatment. Although there are many factors that determine the success of PS therapy, the superiority of treatment modalities in the PS literature is usually analyzed by measuring patient satisfaction, recurrence and complication rates. In the current study, recurrence and complication rates were found to be similar to surgical treatments and adult phenol applications. This finding makes the current study

\begin{tabular}{|l|l|}
\hline \multicolumn{2}{|l|}{ Table II. Data after phenol application } \\
\hline Observation, mo (median) & $31.0(8-68)$ \\
\hline Need for analgesics, d (median) & $2.2 \pm 2.3(0-10)$ \\
\hline $\begin{array}{l}\text { Return to work/school time, d } \\
\text { (median) }\end{array}$ & $0-7(3.9 \pm 2.2)$ \\
\hline Recovery time, d (median) & $14-53(24.4 \pm 6.7)$ \\
\hline $\begin{array}{l}\text { Recurrence rate after one phenol } \\
\text { application, } \mathrm{n}(\%)\end{array}$ & $99 / 26(26.2 \%)$ \\
\hline $\begin{array}{l}\text { Recurrence rate after two phenol } \\
\text { applications, } \mathrm{n}(\%)\end{array}$ & $93 / 13(14.0 \%)$ \\
\hline $\begin{array}{l}\text { Recurrence rate after three phenol } \\
\text { applications, } \mathrm{n}(\%)\end{array}$ & $93 / 10(10.7 \%)$ \\
\hline Total complications, $\mathrm{n}(\%)$ & $15(\% 16.1)$ \\
\hline $\begin{array}{l}\text { Minor complications, } \mathrm{n}(\%) \\
\text { (maceration, superficial burn on the } \\
\text { skin) }\end{array}$ & $11(11.81 \%)$ \\
\hline $\begin{array}{l}\text { Major complications (pus and } \\
\text { cellulitis), } \mathrm{n}(\%)\end{array}$ & $4(4.3 \%)$ \\
\hline Follow-up period in months & $32.2 \pm 24(8-62$ month) \\
\hline Total satisfaction points (average) & $8.7 \pm 1.7(3-10)$ \\
\hline
\end{tabular}


Table III. Factors affecting first recurrence and complications after phenol administration

\begin{tabular}{|c|c|c|c|c|c|c|}
\hline \multirow{4}{*}{ Variables } & \multicolumn{2}{|c|}{$\begin{array}{l}\text { Initial recurrence after phenol } \\
\text { administration }\end{array}$} & \multirow{4}{*}{ p-value } & \multicolumn{2}{|c|}{$\begin{array}{l}\text { Complication after phenol } \\
\text { administration }\end{array}$} & \multirow{4}{*}{ p-value } \\
\hline & \multirow{3}{*}{\begin{tabular}{|l} 
No \\
$n=73$ \\
(mean \pm SD) \\
\end{tabular}} & \multirow{3}{*}{\begin{tabular}{|l} 
Yes \\
$n=26$ \\
(mean \pm SD) \\
\end{tabular}} & & \multirow{3}{*}{$\begin{array}{l}\text { No } \\
n=83 \\
\text { (mean } \pm \text { SD) }\end{array}$} & \multirow{3}{*}{$\begin{array}{l}\text { Yes } \\
n=16 \\
\text { (mean } \pm \text { SD) }\end{array}$} & \\
\hline & & & & & & \\
\hline & & & & & & \\
\hline Age & $17.6 \pm 1.3$ & $17.0 \pm 1.19$ & 0.066 & $17.4 \pm 1.3$ & $17.2 \pm 1.5$ & 0.328 \\
\hline BMI & $25.0 \pm 4.3$ & $25.0 \pm 3.5$ & 0.987 & $25.0 \pm 4.1$ & $25.2 \pm 4.3$ & 0.844 \\
\hline Duration of complaints (months) & $8.5 \pm 9.4$ & $6.5 \pm 4.8$ & 0.166 & $8.1 \pm 8.2$ & $7.5 \pm 10.3$ & 0.788 \\
\hline Natal cleft depth (mm) & $29.9 \pm 11.4$ & $30.7 \pm 11.2$ & 0.756 & $30.7 \pm 11.0$ & $27.3 \pm 13.3$ & 0.271 \\
\hline Number of sinuses & $2.2 \pm 1.2$ & $2.5 \pm 1.3$ & 0.280 & $2.3 \pm 1.3$ & $2.5 \pm 1.4$ & 0.598 \\
\hline Smoking per day & $3.8 \pm 7.3$ & $1.4 \pm 4.4$ & 0.054 & $3.7 \pm 7.2$ & $0.6 \pm 2.5$ & 0.003 \\
\hline $\begin{array}{l}\text { Number of pre-treatment abscess } \\
\text { drainage }\end{array}$ & $0.1 \pm 0.3$ & $0.3 \pm 0.6$ & 0.127 & $0.2 \pm 0.5$ & $0.2 \pm 0.4$ & 0.959 \\
\hline Number of baths per week & $3.5 \pm 1.7$ & $2.8 \pm 1.0$ & 0.114 & $3.4 \pm 1.7$ & $3.3 \pm 1.5$ & 0.870 \\
\hline Categorical variables & n (\%) & n (\%) & ${ }^{*}$ p-value & $n(\%)$ & n (\%) & ${ }^{*}$ p-value \\
\hline \multicolumn{7}{|l|}{ Gender } \\
\hline Male & $52(71.2)$ & $17(65.4)$ & \multirow{2}{*}{0.577} & $59(71.1)$ & $10(62.5)$ & \multirow{2}{*}{0.556} \\
\hline Female & $21(28.8)$ & $9(34.6)$ & & $24(28.9)$ & $6(37.5)$ & \\
\hline \multicolumn{7}{|l|}{ Location of sinus } \\
\hline Midline & $54(74.0)$ & $20(76.9)$ & \multirow{2}{*}{0.766} & $63(75.9)$ & $11(68.8)$ & \multirow{2}{*}{0.542} \\
\hline Midline and lateral & $19(26.0)$ & $6(23.1)$ & & $20(24.1)$ & $5(31.3)$ & \\
\hline \multicolumn{7}{|c|}{ Previous operation before phenol administration } \\
\hline No & $58(79.5)$ & $19(73.1)$ & \multirow{2}{*}{0.502} & $65(78.3)$ & $12(75.0)$ & \multirow{2}{*}{0.750} \\
\hline Yes & $15(20.5)$ & $7(26.9)$ & & $18(21.7)$ & $4(25.0)$ & \\
\hline \multicolumn{7}{|l|}{ Relative has PS } \\
\hline No & $53(72.6)$ & $19(73.1)$ & \multirow{2}{*}{0.963} & $63(75.9)$ & $9(56.3)$ & \multirow{2}{*}{0.129} \\
\hline Yes & $20(27.4)$ & $7(26.9)$ & & $20(24.1)$ & $7(43.8)$ & \\
\hline
\end{tabular}

worthwhile because one of the most important factors in determining the methods to be used in the treatment of PS is the recurrence and complication rates. In this current study, the recurrence rate was $10.7 \%$. Our complication rate was $16.1 \%$ in total and the major complication rate was $4.3 \%$. In a study examining patients in the adolescent age group who were treated with crystallized phenol, both recurrence and complication rates were reported to be $2.5 \%$ with a single application (10). However, recurrences after phenol administration are usually seen after the first year, and the recurrence rates may be low since the mean followup period was only 8.1 months in the study mentioned $(8,13)$. In addition, it is stated in the mentioned study that a good hair cleaning by opening the sinus mouths sufficiently leads to low recurrence rates. Although we applied a similar technique and applied more than one phenol treatment, we could not achieve similar recurrence rates. It is striking that there is only a difference in the form of phenol between the mentioned study and the technique applied in our study. For this reason, we wanted to compare our data with a group of similar age treated with liquid phenol. However, we could not find a study in the literature where liquid phenol was applied to adolescent PS patients. However, we think that the form of phenol used in the treatment (crystallized or liquid) cannot explain this important difference in recurrence rate as crystallized phenol melts rapidly at body temperature and turns into liquid phenol form. 
In the adult literature, the recurrence rates of phenol and its complication rates are reported to be $0-18.6 \%$ $(1,3,14)$ and $0-15.2 \%(3,12,14)$, respectively. As can be seen, the rates of recurrence and complication due to phenol application can be quite different in the literature. It is known that this difference in recurrences varies inversely with the number of phenol applications (3) and in direct proportion to the follow-up period (13). Considering the median follow-up period of 31.0 (8-68) months in the current study, our recurrence rate is consistent with the adult phenol literature. Our complication rate was higher than the adult literature. It is notable that our study showed higher complication rates compared to both adolescent and adult age groups. We have continued our experience in adolescents as we use liquid phenol in adult PS patients and because liquid phenol can be easily directed to the desired area by absorbing it in swab cotton. However, since we make multiple applications in the same session with phenol-impregnated swab wipes, the substances protecting the skin can be removed during repetitive procedures. These findings indicate that more attention should be paid to the protection of surrounding tissues, especially during multiple liquid phenol applications.

In order to compare the recurrence and complication rates in the current study with surgical methods in the literature, we preferred the surgical methods that are frequently used in the treatment of PS in the world. While the most commonly used are excision and open wound healing or primary closure in the midline, the Karydakis flap and Limberg flap are commonly used for off-midline procedures (1). The recurrence and complication rates of the above mentioned surgical treatments vary between 1.4-45\% and $8.9-49 \%$ in the literature $(5,9,10,15-19)$. We think that recurrence rates in our study provide acceptable rates when compared with the surgery groups used in the treatment of PS in the literature. In addition, because the anatomy is not impaired after the application of phenol, the application can be easily repeated at an out-patient hospital. However, one disadvantage of phenol is that in order to achieve high success rates, it can be said that it usually requires multiple applications as in our study (3). Although the complication rates in our study are not lower than for surgical treatments in the literature, our major complications are usually easily treated complications such as abscess and cellulitis. After surgical treatment, complete wound separation due to abscess, seroma and hematoma may be seen (20) and sometimes complications resulting from surgery result in more morbidity than the disease itself (21). In addition, the disadvantages of the aforementioned surgical treatments include the need for patients to be admitted to hospital $(5,7,21,22)$ and the difficulty of completing the learning curve of flap methods (1). The phenol method is a technique that is easy to apply, does not require hospitalization and whose learning curve is shorter.

When we evaluated the patients in our study in terms of recurrence and complications, a correlation was found only between smoking and the development of complications. However, in studies evaluating recurrence and complications after PS surgery in the literature, the onset of symptoms, sinus number, and BMI were found to be risk factors $(23,24)$. Recurrence and complications were not affected by the characteristics of the patient in general, probably because the anatomy did not change in our treatment with phenol and only the diseased area was intervened.

The second important issue we investigated in our study was the satisfaction rates of the patients. Total satisfaction rates are determined by patient tolerability, complication rates, postoperative pain, quick return to daily work/school and cosmetic results. The satisfaction rates of the adolescents in our study were found to show some differences in terms of patient satisfaction when compared with the adult phenol applications in literature and the frequently used surgical applications in the treatment of PS. In a study comparing the $40-80 \%$ liquid phenol administration in adult PS patients (25), the recovery times were similar to our study, while return to work/school and use of painkillers lasted for a shorter period than for our patients. These differences may be explained by the use of prolonged pain killer because of the increased pain due to the more active life of the adolescent age group. In addition, adolescents who are already in school life may not feel the necessity to start school, while adults who have a business life are obliged to start working as soon as possible. This may explain why adolescents with similar wound healing times return to work/school after longer periods of time. Compared with the surgical techniques commonly used in the treatment of PS in the literature, patient satisfaction rates $(5,26,27)$ are comparable with wound healing times $(6,28,29)$, however, it can be seen that the current study is more advantageous than the surgical treatments in terms of return to work $(6,7,30-33)$ and use of painkillers $(7,21)$.

Considering the advantages of phenol therapy, the satisfaction rates in the current study were found to be similar to the satisfaction rates of the surgical groups. This finding is consistent with the study conducted by Doll et al. (26). Doll et al. (26) stated that patients did not care about a long hospital stay or a long wound healing 
period if there was no recurrence and they did not find a relationship between different surgical PS treatment methods and satisfaction. In addition, they reported that the age of the patient at the time of surgery did not affect patient satisfaction, but the average satisfaction rate of patients under 20 years of age was lower than the total average, in addition, patients without recurrence had higher satisfaction rates than those with recurrence. Since the patients in our study were in the adolescent age group and the rates of recurrence were found to be comparable with the surgery groups, we thought that we obtained similar satisfaction rates to the surgical groups.

Finally, another point worth mentioning is the use of surgical prophylactic antibiotics (SP) to which though we have not paid due attention while comparing phenol treatment with surgical methods. While SP is usually applied to surgical methods $(1,21,34)$, during the administration of phenol, there is no administration of SP if the patient does not have diabetes mellitus or immunosuppression $(3,25,35)$. This situation is important in terms of antibiotic resistance that threatens the world and also provides an advantage in terms of patient cost.

\section{Study Limitations}

The study was retrospective. In addition, the fact that a small number of patients did not accept invitation to the polyclinic, the case if there were recurrence or not were defined according to their own declaration. This may have led to the omission of asymptomatic recurrences.

\section{Conclusion}

This study is important in terms of showing that $80 \%$ liquid phenol application is a method that can be used in the treatment of adolescent PS in comparison with the commonly used surgical methods and phenol applications in adults in the literature. Although $22.2 \%$ of the patients in our study were previously surgically treated recurrent patients, they provided similar recurrence rates to surgical treatments and adult phenol applications in the literature. In addition, low rates of major complications, less anatomical changes compared to surgical methods, and rapid return to work/ school are among the important advantages of the method. For all these reasons, we think that phenol application should be recommended as the first treatment method in patients with primary and postoperative recurrent PS. For stronger evidence, prospective randomized reports with high volume and long-term follow-up are recommended to compare with surgical methods in this age group.
Ethics

Ethics Committee Approval: Local ethics committee approval (26.09.2018-252) was obtained for this study.

Informed Consent: Written informed consent was obtained from all patients before the procedure.

Peer-review: Externally peer-reviewed.

\section{Authorship Contributions}

Concept: C.K., Design: C.K., Data Collection or Processing: A.S., M.M., Analysis or Interpretation: I.S., M.E., Literature Search: C.K., A.S., M.E., M.M., H.B.D., I.S., G.K., C.A., Writing: C.K., M.M.

Conflict of Interest: No conflict of interest was declared by the authors.

Financial Disclosure: The authors declared that this study received no financial support.

\section{References}

1. lesalnieks I, Ommer A, Petersen S, Doll D, Herold A. German national guideline on the management of pilonidal disease. Langenbecks Arch Surg 2016; 401:599-609.

2. Akinci OF, Coskun A, Uzunköy A. Simple and effective surgical treatment of pilonidal sinus. Dis Colon Rectum 2000; 43:701-6.

3. Emiroğlu M, Karaali C, Esin H, Akpınar G, Aydın C. Treatment of pilonidal disease by phenol application. Turk / Surg 2017; 33:5.

4. Can MF, Sevinc MM, Yilmaz M. Comparison of Karydakis flap reconstruction versus primary midline closure in sacrococcygeal pilonidal disease: results of 200 military service members. Surg Today. 2009; 39:580-6.

5. Käser S, Zengaffinen R, Uhlmann M, Glaser C, Maurer C. Primary wound closure with a Limberg flap vs. secondary wound healing after excision of a pilonidal sinus: a multicentre randomised controlled study. Int J Colorectal Dis 2015; 30:97-103.

6. Keshvari A, Keramati MR, Fazeli MS, Kazemeini A, Meysamie A, Nouritaromlou MK. Karydakis flap versus excision-only technique in pilonidal disease. I Surg Res 2015; 198:260-6.

7. Ozcan R, Hüseynov M, Bakır AC, et al. Which treatment modality for pediatric pilonidal sinus: primary repair or secondary healing? Asian J Surg 2018; 41:506-10.

8. Calikoglu I, Gulpinar K, Oztuna D, et al. Phenol injection versus excision with open healing in pilonidal disease: a prospective randomized trial. Dis Colon Rectum 2017; 60:161-9.

9. lesalnieks I, Ommer A, Petersen S, Doll D, Herold A. German national guideline on the management of pilonidal disease. Langenbecks Arch Surg 2016; 401:599-609.

10. Ates $U$, Ergun E, Gollu G, et al. Pilonidal sinus disease surgery in children: the first study to compare crystallized phenol application to primary excision and closure. J Pediatr Surg 2018; 53:452-5.

11. Girgin $M$, Kanat BH, Ayten R, et al. Minimally invasive treatment of pilonidal disease: crystallized phenol and laser depilation. Int Surg 2013; 97:288-92. 
12. Gulpinar K, Pampal A, Ozis SE, Kuzu MA. Non-operative therapy for pilonidal sinus in adolescence: crystallised phenol application,'report of a case'. BMJ Case Rep 2013;2013:bcr2012008382. doi: 10.1136/bcr-2012-008382.

13. Doll D. 5-and 10-year recurrence rate is the new gold standard in pilonidal sinus surgery benchmarking. Med Princ Pract 2010; 19:216-7.

14. Calikoglu I, Gulpinar K, Oztuna D, et al. Phenol injection versus excision with open healing in pilonidal disease: a prospective randomized trial. Dis Colon Rectum 2017; 60:161-9.

15. Can MF, Sevinc MM, Yilmaz M. Comparison of Karydakis flap reconstruction versus primary midline closure in sacrococcygeal pilonidal disease: results of 200 military service members. Surg Today 2009; 39:580-6.

16. Erkent $M$, Şahiner IT, Bala $M$, et al. Comparison of primary midline closure, limberg flap, and karydakis flap techniques in pilonidal sinus surgery. Med Sci Monit 2018; 24:8959-63.

17. Hardy EJO, Herrod P), Doleman B, Phillips HG, Ranat R, Lund JN. Surgical interventions for the treatment of sacrococcygeal pilonidal sinus disease in children: a systematic review and meta-analysis. J Pediatr Surg 2019; 54:2222-33.

18. Okuş A, Sevinç B, Karahan Ö, Eryılmaz MA. Comparison of Limberg flap and tension-free primary closure during pilonidal sinus surgery. World I Surg 2012; 36:431-5.

19. Tokac M, Dumlu EG, Aydin MS, Yalcin A, Kilic M. Comparison of modified Limberg flap and Karydakis flap operations in pilonidal sinus surgery: prospective randomized study. Int Surg 2015; 100:870-7.

20. Keshava A, Young C), Rickard MIX, Sinclair G. Karydakis flap repair for sacrococcygeal pilonidal sinus disease: how important is technique? ANZ J Surg 2007; 77:181-3.

21. Tokac M, Dumlu EG, Aydin MS, Yalcın A, Kilic M. Comparison of modified Limberg flap and Karydakis flap operations in pilonidal sinus surgery: prospective randomized study. Int Surg 2015; 100:870-7.

22. Sevinç B, Karahan Ö, Okuş A, Ay S, Aksoy N, Şimşek C. Randomized prospective comparison of midline and off-midline closure techniques in pilonidal sinus surgery. Surgery 2016; 159:749-54.

23. Onder A, Girgin S, Kapan M, et al. P ilonidal sinus disease: risk factors for postoperative complications and recurrence. Int Surg 2012; 97:224-9.
24. Arda is, Güney LH, Sevmiş \$̧, Hiçsönmez A. High body mass index as a possible risk factor for pilonidal sinus disease in adolescents. World I Surg 2005; 29:469-71.

25. Emiroglu M, Karaali C, Salimoglu S, Sert I, Ugurlu L, Aydın C. The effect of phenol concentration on the treatment of pilonidal sinus disease: early results of a prospective randomized study. Int Surg 2016; 101:127-32.

26. Doll $D$, Luedi MM, Evers $T$, Kauf $P$, Matevossian E. Recurrencefree survival, but not surgical therapy per se, determines 583 patients' long-term satisfaction following primary pilonidal sinus surgery. Int I Colorectal Dis 2015; 30:605-11.

27. Karakayali F, Karagulle E, Karabulut Z, Oksuz E, Moray G, Haberal $M$. Unroofing and marsupialization vs. rhomboid excision and Limberg flap in pilonidal disease: a prospective, randomized, clinical trial. Dis Colon Rectum 2009; 52:496-502.

28. Kaplan M, Ozcan O, Bilgic E, Kaplan ET, Kaplan T, Kaplan FC. Distal scar-to-midline distance in pilonidal Limberg flap surgery is a recurrence-promoting factor: a multicenter, case-control study. Am / Surg 2017; 214:811-9.

29. Varnalidis I, loannidis O, Paraskevas G, et al. Pilonidal sinus: a comparative study of treatment methods. J Med Life 2014; 7:27.

30. Ahmed AK, McCallum I, King PM, Bruce J. Healing by primary versus secondary intention after surgical treatment for pilonidal sinus. Cochrane Database Syst Rev 2010; 2010:CD006213. doi: 10.1002/14651858.CD006213.pub3.

31. McCallum I, King PM, Bruce I, Ahmed AK. Healing by primary versus secondary intention after surgical treatment for pilonidal sinus. Cochrane Database Syst Rev 2007: CD006213. doi: 10.1002/14651858.CD006213.pub2.

32. McCallum IJ, King PM, Bruce J. Healing by primary closure versus open healing after surgery for pilonidal sinus: systematic review and meta-analysis. BMJ 2008; 33:868-71.

33. Unalp HR, Derici H, Kamer E, Nazli O, Onal MA. Lower recurrence rate for Limberg vs. VY flap for pilonidal sinus. Dis Colon Rectum 2007; 50:1436-44.

34. Karakaş B, Aslaner A, Gündüz $U$, et al. Is the lateralization distance important in terms in patients undergoing the modified Limberg flap procedure for treatment of pilonidal sinus? Tech Coloproctol 2015; 19:309-16.

35. Dogru O, Camci C, Aygen E, Girgin M, Topuz Ö. Pilonidal sinus treated with crystallized phenol. Dis Colon Rectum 2004; 47:1934-8 